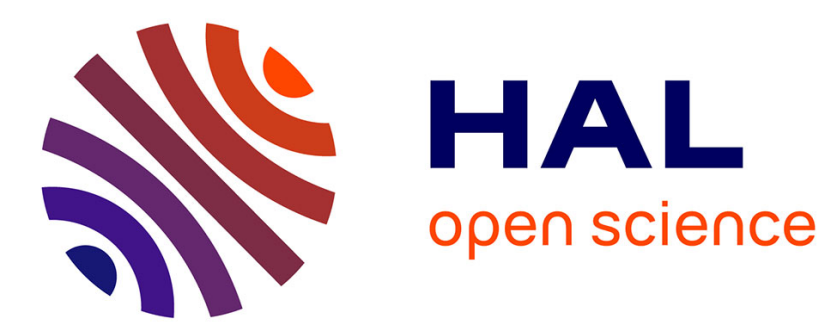

\title{
Living Conditions and Turn-Over in Personal Networks During the First COVID-19 Lockdown in France
}

Marie-Pierre Renée Bes, Claire Bidart, Adrien Defossez, Guillaume Favre, Julien Figeac, Michel Grossetti, Lydie Launay, Nicolas Mariot, Pierre Mercklé, Béatrice Milard, et al.

\section{To cite this version:}

Marie-Pierre Renée Bes, Claire Bidart, Adrien Defossez, Guillaume Favre, Julien Figeac, et al.. Living Conditions and Turn-Over in Personal Networks During the First COVID-19 Lockdown in France. SSRN Electronic Journal, 2021, 10.2139/ssrn.3807975 halshs-03506334

\section{HAL Id: halshs-03506334 \\ https://shs.hal.science/halshs-03506334}

Submitted on 4 Jan 2022

HAL is a multi-disciplinary open access archive for the deposit and dissemination of scientific research documents, whether they are published or not. The documents may come from teaching and research institutions in France or abroad, or from public or private research centers.
L'archive ouverte pluridisciplinaire HAL, est destinée au dépôt et à la diffusion de documents scientifiques de niveau recherche, publiés ou non, émanant des établissements d'enseignement et de recherche français ou étrangers, des laboratoires publics ou privés. 


\title{
Living Conditions and Turn-Over in Personal Networks during the First COVID-19 Lockdown in France
}

Marie-Pierre Bès ${ }^{1}$, Claire Bidart ${ }^{2,3}$, Adrien Defossez ${ }^{1}$, Guillaume Favre ${ }^{1}$, Julien Figeac ${ }^{1,2}$, Michel Grossetti $^{1,2,4}$, Lydie Launay ${ }^{1}$, Nicolas Mariot ${ }^{4}$, Pierre Mercklé ${ }^{5}$, Béatrice Milard ${ }^{1}$, Anton Perdoncin ${ }^{4}$, Benoit Tudoux ${ }^{2,6}$

\footnotetext{
${ }^{1}$ University of Toulouse, FRANCE

${ }^{2}$ CNRS, FRANCE

${ }^{3}$ University of Aix-Marseille, FRANCE

${ }^{4}$ EHESS, FRANCE

${ }^{5}$ University of Grenoble Alpes, FRANCE

${ }^{6}$ University of Paris Nanterre, FRANCE
}

Corresponding author: Michel Grossetti, michel.grossetti@,univ-tlse2.fr

\begin{abstract}
.
This working paper presents the main results of a national survey carried out in France between 14 April and 10 May 2020. To fight the pandemic, the French government has introduced policies aimed at limiting travel by the French, for example by encouraging companies to make extensive use of telecommuting. This survey analyzes the social, economic and political issues of this first lockdown in France by focusing on respondents' living conditions, sense of well-being, experience of gender inequalities, telecommuting hardships, and compliance with health rules, as well as their interpersonal relations (including the ways in which the lockdown increased social isolation or, conversely, promoted social support via ICT use). The main findings of this survey are summarized in this working paper.
\end{abstract}

Keywords: COVID-19; National Survey; Lockdown; France; Livings conditions; Well-being; Social support network; Social isolation. 


\section{Introduction}

The generalised confinement of the population, such as that experienced in France between 17 March and 10 May 2020, constitutes a novel situation that has not failed to raise questions for social science researchers (sociologists, political scientists, anthropologists, historians, economists, etc.) in various aspects: functioning of the health system; limitation of freedoms; constraints on economic activity; housing inequalities, etc. This explains why a very large number of surveys were launched during the period.

We are a small group of sociologists ${ }^{1}$, most of us interested in interpersonal relations, in the tradition of social network analysis, and for others in political activities, housing, gender relations or work. We took the initiative of a survey on which we started working on March 26th and which resulted in a questionnaire put online on April 14th, with data collection ending on May 10th. In order to disseminate it, we mobilised a network of colleagues and their students as well as the Daily Regional Press, several editorial offices of which agreed to distribute calls for responses to the survey. This enabled us to reach a relatively high number of questionnaires (more than 16,000) for this type of survey.

The questionnaire includes a number of complementary issues. In addition to the classic questions on socio-economic characterisation (age, sex, occupation, level of education, family situation, etc.), it naturally includes questions on the confinement itself (change of living place or not, housing conditions) and on work during this period (technical unemployment or redevelopment, teleworking or presence in the usual places, etc.). It also includes questions about going out, health protection measures, the relationship with the limits imposed by confinement (on travel, for example) and the expression of feelings caused by the situation (tiredness, anxiety, sadness, etc.). An important part of the survey concerns social relations (new contacts, lost contacts, strengthened relations).

We have a sample in which graduates, women and under $75 \mathrm{~s}$ are over-represented, while certain categories of the population are very poorly represented (male workers for example). The large size and diversity of the sample, however, makes it possible to analyse variations according to age, gender, occupational categories, family and confinement configurations or work situation. It should be borne in mind, however, that our survey involved the use of the Internet and therefore leaves out certain parts of the population: people without access to online activities, those who speak French poorly, but also very wealthy people who generally do not take the time to answer this type of survey, or others who are hostile for various reasons to studies such as this one. Our analyses obviously try to take these limitations into account as much as possible and to compare our results with those of other studies.

\section{Housing conditions are decisive for the experience of lockdown}

Lockdown is a form of house arrest, resulting in most people having to spend much more time than usual in their homes. For those who are teleworking, this means carrying out work activities, for those with children, school supervision activities, and for those who are used to having their meals outside, at least at lunchtime, cooking more than usual. Housing is therefore an important element in the situation of people in such situations.

$57.4 \%$ of the people who answered the question on the type of housing were living in singlefamily houses, $43 \%$ in a flat, with those who preferred to answer something else most often citing student residences or maids' rooms. The proportion of owners is $59.5 \%$.

${ }^{1}$ Thanks to Emilie Vrain, University of East Anglia (UK), for her help in this English adaptation of the first synthesis of our results. 


\subsection{Who has left home to be confined elsewhere?}

Some of the respondents left house for confinement. $8.2 \%$ are in this case. This proportion should be modulated by the fact that $15.6 \%$ of those who said they had changed dwelling stated that they had moved "to their usual residence or that of their spouse", most often that of their spouse. There may be cases of people who were in temporary housing for work and returned home for confinement.

The proportion of people who have changed accommodation is particularly high among young people $(26.4 \%$ for the $18-30$ age group, who account for $69.8 \%$ of people who have changed accommodation, with the proportion of people changing accommodation being around 3 or $4 \%$ for the other age groups). Around two thirds (64.4\%) of young people who have changed accommodation have moved to their parents' home, or to their spouse's home if they are in a couple, and have settled there with their parents. Sometimes $(13.6 \%)$ they moved into their parents' home when their parents were not there.

Apart from the case of young people, it can be observed that the most qualified over 45 year olds changed their place of residence more frequently than others for confinement. This trend is particularly marked when people are teleworking or not working. On the other hand, the use of secondary residences increases with age and level of education (i.e. with income and wealth levels).

Housing is one of the elements that correlates with being confined outside one's usual home. Thus, while $41.5 \%$ of students have been confined outside their usual accommodation (students represent $44.2 \%$ of those in this case), the proportion is even higher when the person does not live with a spouse (single or in a couple without cohabitation), has at least the baccalaureate $(48.2 \%)$, and in addition lives in a appartment block (61.4\%), and is aged between 18 and 24 (65.5\%).

Simplifying a little, we can say that the change of housing is particularly frequent for people living alone in a flat before the confinement and in those periods of life when it is common to return to one's family (see following graph).

Figure 1. Changing accommodation for lockdown by age and whether or not alone

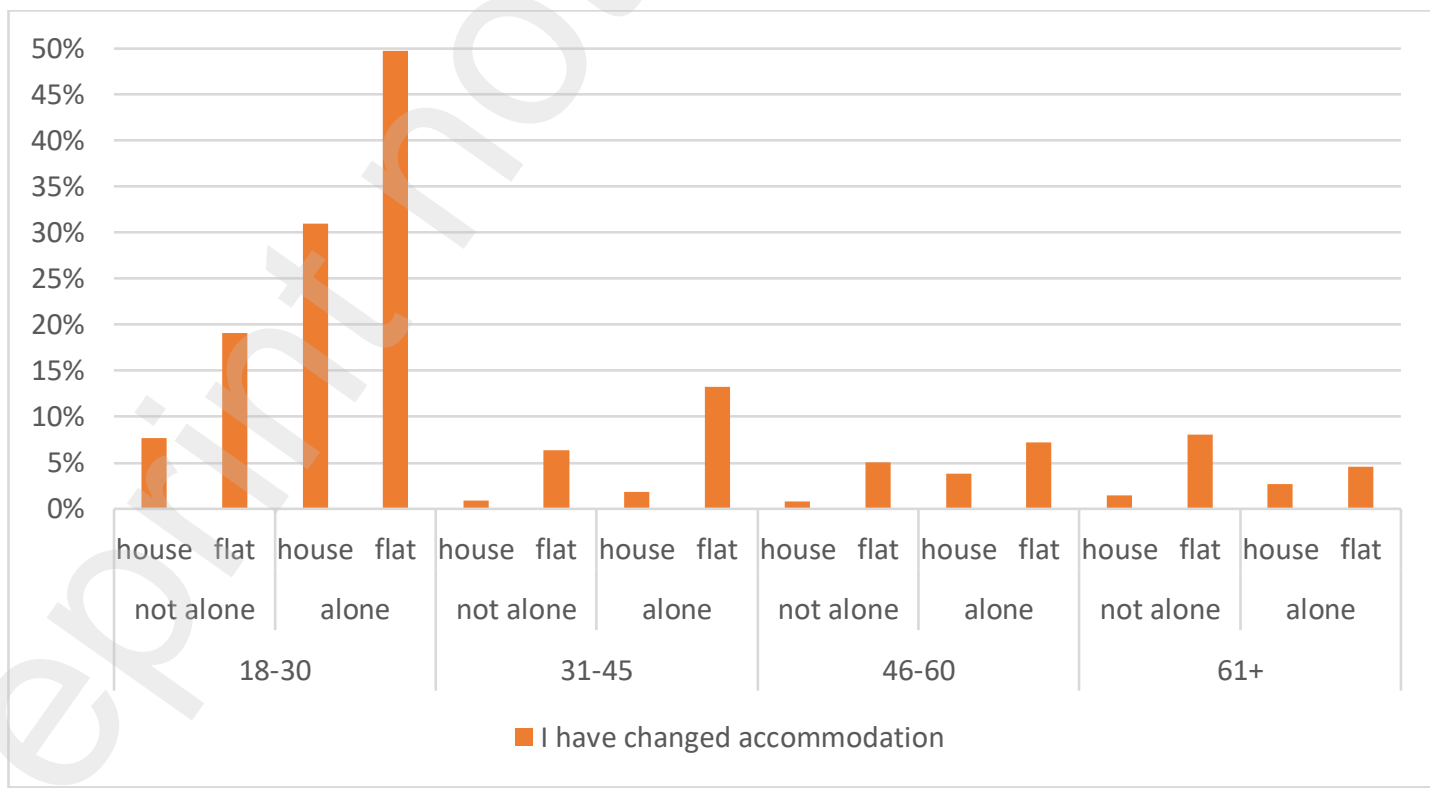

Source: Vico survey, April-May 2020.

Field: Respondents aged 18 and over usually residing in France $(\mathrm{N}=16,224)$.

Reading: $7.7 \%$ of the $18-30$ year olds who lived in a house with other people before confinement changed accommodation. 


\subsection{Have housing-related problems been altered by confinement?}

The questionnaire included a question on housing problems during confinement: "In the housing in which you are confined and its environment, are you currently experiencing one or more of the following problems? ». This was followed by a series of answers which respondents could tick as many as they wished.

Responses indicating problems are more frequent for people who have stayed in their housing and only have a maximum of one room per person, including of course the lack of space inside the dwelling. Only $27 \%$ of the inhabitants of the disavantaged areas did not mention any problems, while $46.7 \%$ of the inhabitants of the apartment blocks located in inner cities outside the disavantage areas mentioned no problems, $52.4 \%$ of the inhabitants of mixed housing areas, $70.6 \%$ of the inhabitants of the residential neighbourhoods in suburban areas and $79.3 \%$ of the inhabitants of the housing areas outside the urban areas. It is clearly in the appartments blocks, and particularly in the disavantaged areas, that the respondents ticked off the most problems.

Some of the problems are particularly relevant to the disavantage neighrourhoods and residential block districts: pollution outside the dwelling; lack of safety outside the dwelling; dirt on the streets or in the neighbourhood; difficulties in finding certain basic foodstuffs; noise pollution outside the dwelling (noise from the street, from neighbours); noise pollution inside the dwelling (noise from other occupants of the dwelling). Other problems are related to the conditions of lockdown. Tensions or conflicts with occupants of the dwelling; lack of space inside the dwelling.

In the disavantaged neighbourhoods, the confinement was particularly difficult, but it is not possible at this stage of the analysis to know whether it constituted a worsening of the usual situation of the people concerned.

Figure 2. Housing problems by type of neighbourhood

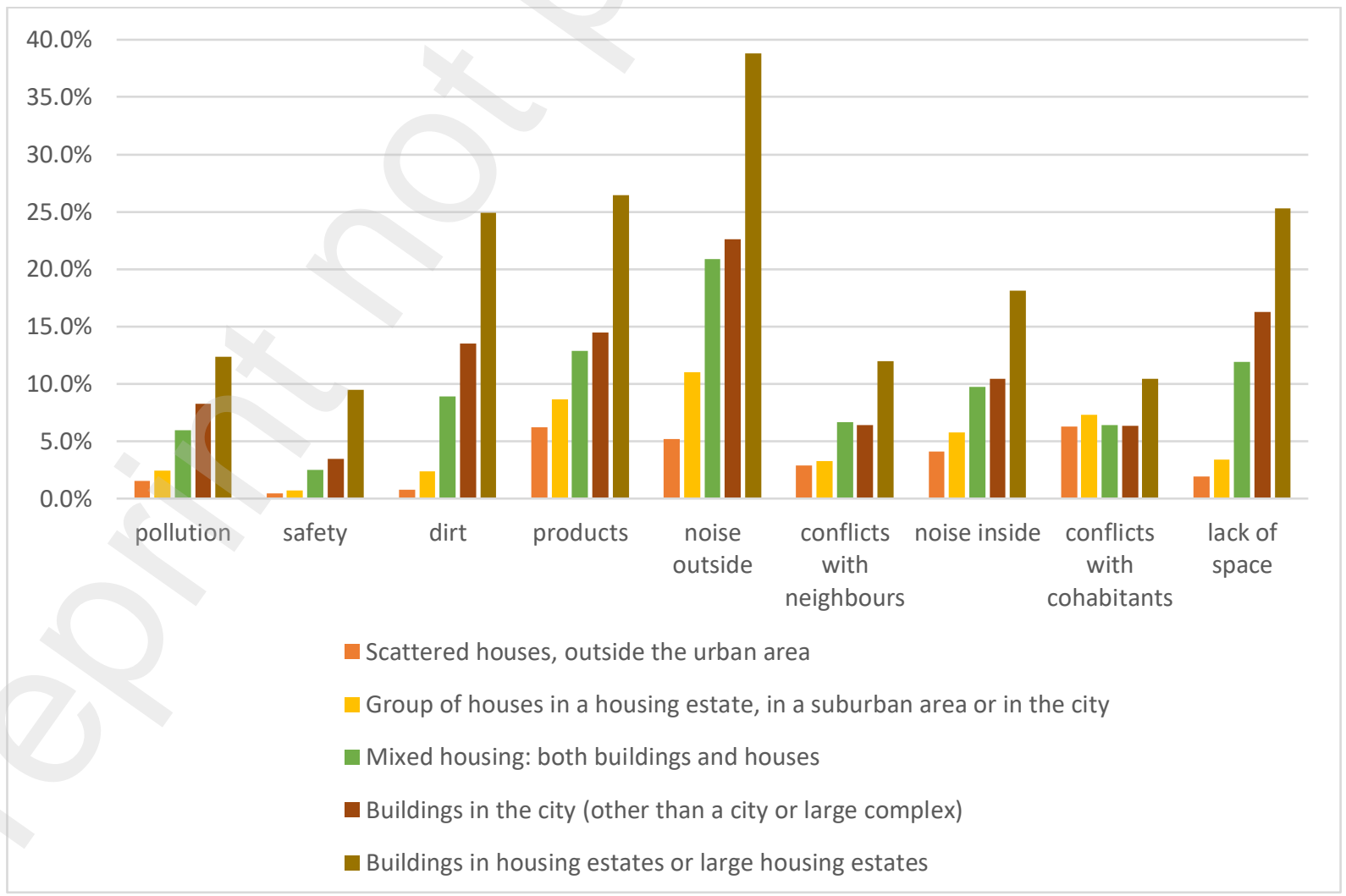

Source: Vico survey, April-May 2020.

Field: Respondents aged 18 and over usually residing in France $(\mathrm{N}=16,224)$. 
Reading: $1.6 \%$ of people confined to an area made up of scattered houses mention pollution problems.

Beyond the case of disavantaged areas, the density of settlement seems to have favoured different types of problems, except those concerning conflicts between people confined together. Even access to food seems to have been more difficult in building districts than in dispersed housing environments. The size of the dwelling was also an important factor, with the smaller dwellings being associated with more problems.

\subsection{Relations with neighbours: more or less ties in the period?}

Relations with neighbours were an important element of the period. One of our questions was: "Since the beginning of the lockdown, have you ever had any discussions with neighbours or people with whom you are not usually in a relationship? ». $34.5 \%$ of the respondents answered positively.

Sometimes relations with neighbours have deteriorated and these appear in the answers to the question "Are there people with whom relations have deteriorated since the confinement (including people with whom you are confined)? ». For the 18-30 year olds, men ticked twice as many times as women ticked this answer. For the 31-60 year olds, the answer is particularly frequent when people live in a flat. For those over 60, the frequency is significantly higher for those who are confined as a couple without any other person. In most cases, the cause of the degradation is conflict. The proportion of positive answers to the question on whether neighbours are a problem depends very much on the type of neighbourhood, lowest in dispersed housing, highest in disavantaged areas (especially for couples with children) and in mixed housing blocks or neighbourhoods for workers in large provincial cities.

It also happens that neighbours are cited in response to the types of relationships that are lost sight of. This is common among those over 60 years of age confined to large houses or flats $(22.6 \%)$, who do not work $(25.4 \%)$, probably because they have not gone out much and have crossed paths less often with their neighbours.

Finally, for those who said they had established new relationships (20.5\% of the total), neighbours represent two thirds $(64.5 \%)$ of the responses to the question on types of contact, which gives an idea of the strengthening of neighbourhood ties. To the question on the people with whom the respondents were already in contact and to whom they became closer during the confinement, the responses concerned neighbours in some cases, particularly for people confined to individual houses.

To sum up, people living in single-family housings already had more relationships with neighbours (than those in collective dwellings) before confinement, and they came closer to them more often during confinement, even if some were lost to view, whereas those in collective dwellings increased their interactions with neighbours, sometimes making new contacts, sometimes finding themselves involved in conflicts. In the disavantaged areas, the neighbourhood environment, which was already problematic before lockdown, remained problematic during lockdown and even proved to be even more difficult.

\subsection{With whom are the respondents confined?}

The spouse and children (the nuclear family) were the most frequent confinement companions. 


\section{Figure 3: Confined with whom? (multiple answers possible)}

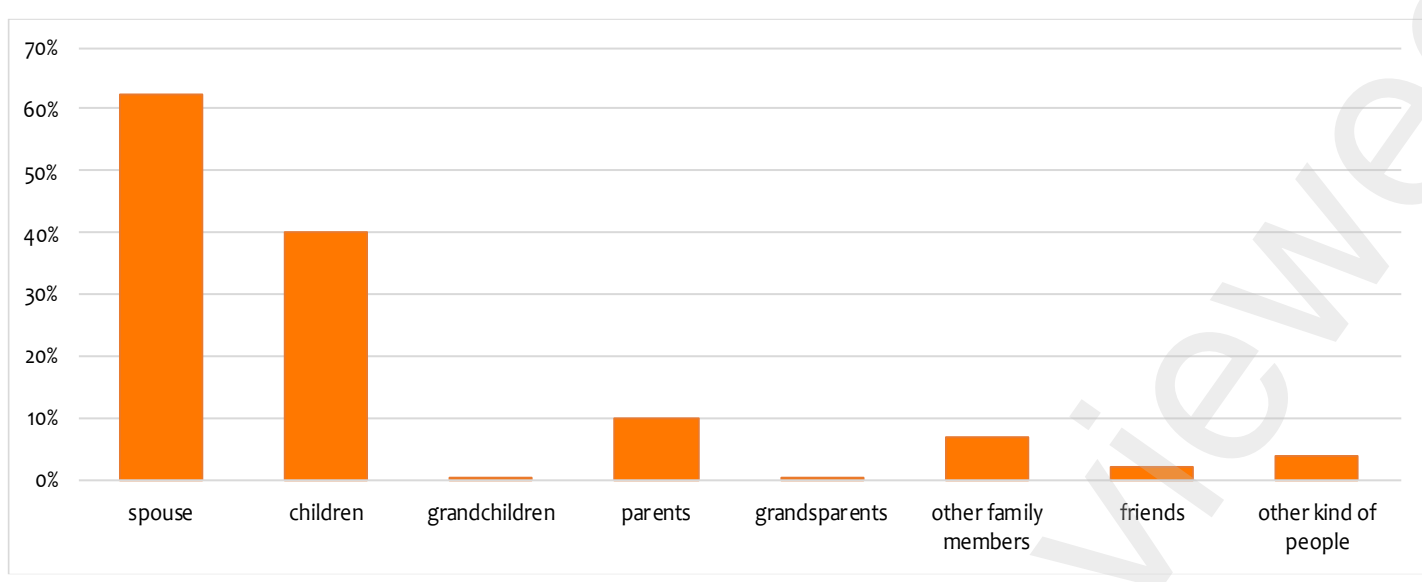

Source : Enquête Vico, avril-mai 2020.

Champ : Répondant.es de 18 ans et plus résidant habituellement en France ( $\mathrm{N}=16$ 224).

Lecture : $62,2 \%$ des répondant.es sont confiné.es avec leur conjoint.

If we combine the information on the people present with the respondents during the lockdown, we obtain what is shown in the following graph as a function of age. Young people were often confined with persons other than their spouse or children, usually their parents or in-laws, particularly because a large proportion of them were brought to join their family for confinement, with the intermediate age groups often being couples with children, the proportion of those confined alone increasing with age.

\section{Figure 4: Age-specific lockdown configuration}

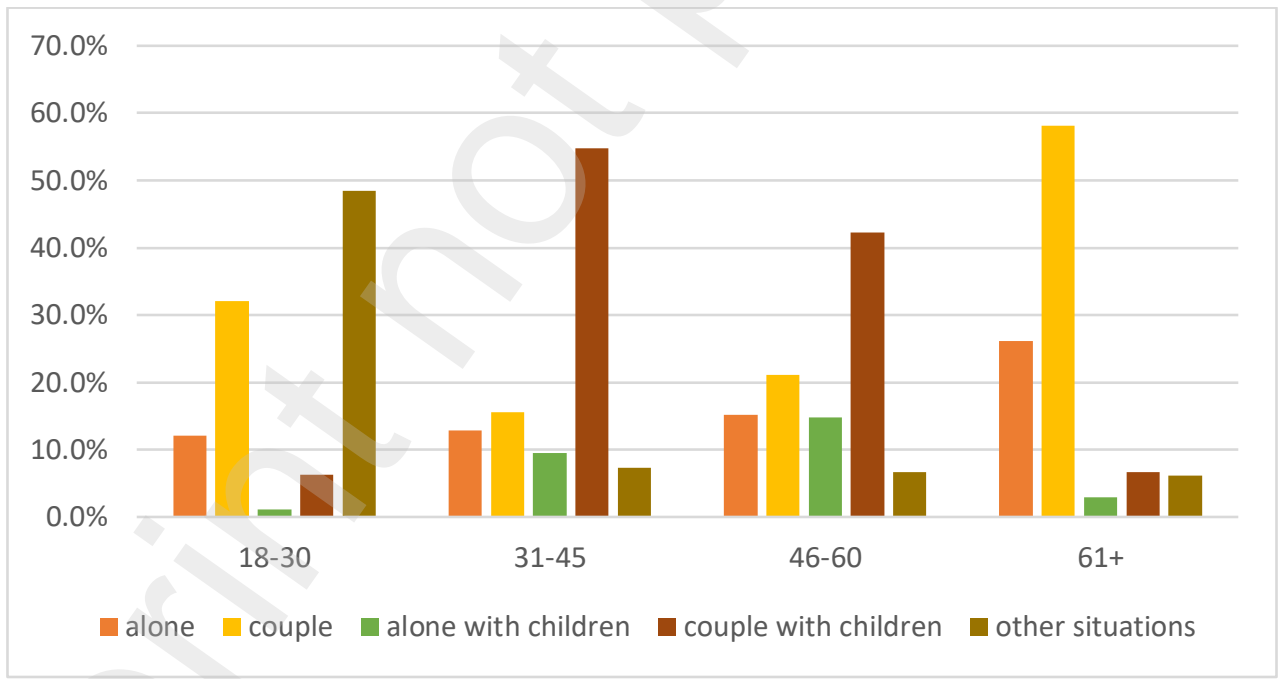

Source: Vico survey, April-May 2020.

Field: Respondents aged 18 and over usually residing in France $(\mathrm{N}=16,224)$.

Reading: $12.1 \%$ of $18-30$ year olds lived alone during lockdown.

Being confined alone with children was twice as frequent for women as for men $(9.1 \%$ compared to $4.4 \%$ ), which is obviously explained by the higher proportion of women among single-parent families. The men in the sample were more often in couples without children $(35.6 \%$ versus $26.3 \%$ ) than the women, who were more often in couples with children $(32.9 \%$ versus $27.4 \%)$. 
Around $20 \%$ of adults live alone in France. In our data it is a little more $(22 \%)$ because we have more young people (and for the older ones no one in an institution). But the proportion of people confined alone is more like $16 \%$, which means that some of the people who usually live alone have been confined with other people. Many of them are students or young people who have no work-related constraints (because they can telework or have stopped their activities during lockdown There are also couples whose members do not usually reside together and who have chosen to come together for lockdown. In the following graph, people usually living alone who have confined themselves with others have not necessarily changed accommodation, they may have been joined at home by others.

\section{Figure 5: Resided alone before lockdown and confined with others, by age}

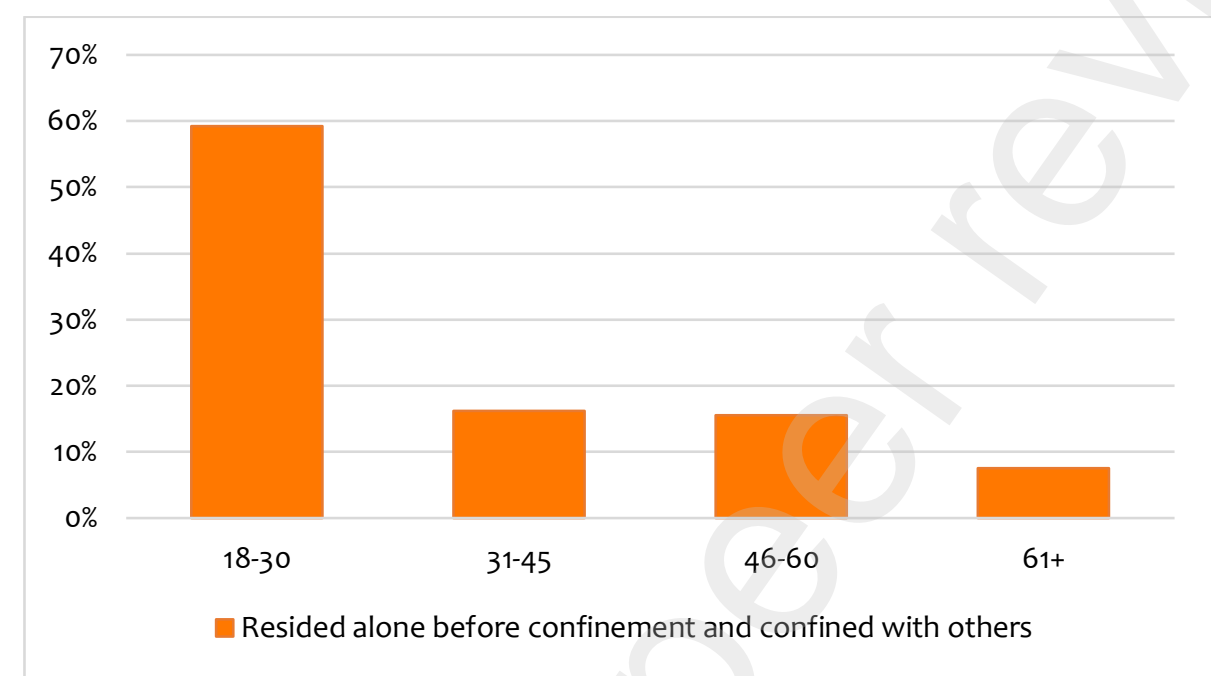

Source: Vico survey, April-May 2020.

Field: Respondents aged 18 and over usually residing in France $(\mathrm{N}=16,224)$.

Reading: $59.3 \%$ of $18-30$ year olds who lived alone before lockdown confined themselves with other people.

\section{The work situation particularly affected by the crisis}

What was the situation during the lockdown of the people who responded to our questionnaire and who had a job before? ${ }^{2}$

\subsection{More than half of the working people have seen their working conditions change.}

1. Very few people were made unemployed $\left(0.6 \%\right.$ of those in employment ${ }^{3}$ who responded to our questionnaire). The proportion is higher especially among blue-collar workers $(4.6 \%$ of dismissals within this occupational category) and private employees (more than $3 \%$ ) as well as craftsmen and shopkeepers $(2.7 \%)$.

2. Significantly more people have been given one or more days off $(19 \%)$. This is particularly the case for the intermediate professions in the private sector $(23.1 \%)$ and professional and managerial staff in the private sector $(26.8 \%)$. It is also more frequent for men. $12.4 \%$ say they

\footnotetext{
2 Our sample includes more people teleworking or stopping work at the time of lockdown than in the French population. For a comparison with a more representative sample, see the EpiCov survey (https://www.iresp.net/wpcontent/uploads/2020/10/IReSP_QSP40.web_.pdf).

3 All percentages in this section are calculated in relation to the 10369 respondents who were employed before the lockdown.
} 
have seen their working conditions deteriorate, while $8.6 \%$ have suffered a significant loss of income.

3. Even more numerous are the people placed on partial or total technical unemployment (23.5\%). The proportion decreases with age (34.3\% for the $18-30$ year olds to $13.5 \%$ for those over 60). $48.1 \%$ of people in this situation did not work at all during the period, $38.5 \%$ were in total or partial telework and only 13.5\% worked outside the home. The proportion of people in this situation is particularly high in the private sector: $36.6 \%$ for the intermediate professions in this sector, $48.3 \%$ of people who declared themselves to be "administrative or commercial employee in a company (reception agent, secretary, office employee, control" (55.6\% for the 18-30 year olds) and $58.7 \%$ of those who ticked the answer "Employee in direct services to individuals (waiter, cleaning lady, childcare assistant, salaried hairdresser)", 55.7\% of manual workers. For $6 \%$ this situation was accompanied by a deterioration in working conditions and for $19 \%$ by a significant reduction in income.

$6.1 \%$ of those surveyed had to face both leave and technical unemployment (a third of the former, a quarter of the latter). $3.8 \%$ of those who were on leave also experienced a reduction in working time (see below). In all, $36.3 \%$ of those surveyed experienced one or other of these unemployment situations.

4. 16.3\% experienced a decrease in working time (for employees) or a decrease in activity (for the self-employed). This is particularly common among craftsmen and shopkeepers $(44.7 \%)$. For $15.7 \%$, this situation was accompanied by a deterioration in working conditions and $30.5 \%$ saw their income decrease significantly.

5. Some (just over one percent) have returned to work while they were on leave, on holiday or inactive before the start of lockdown, often for work outside the home $(43.3 \%$ of them are in this situation compared with $20.1 \%$ for all those in employment and $2.6 \%$ of those working outside the home are people in this situation of returning to work). For $22.1 \%$ this situation was accompanied by a deterioration in working conditions and for $6.6 \%$ by a significant decrease in income.

6. Others (4.3\%) experienced an increase in their compulsory working hours. Here too it was more a case of working on the spot: $44.7 \%$ of those who were in this situation worked on the spot and $9.7 \%$ of those who were working on the spot faced an increase in their working time. They were particularly numerous $(7.3 \%)$ among the intermediate professions of teaching, health, the civil service (school teachers, educators, etc.) and managers in the public sector $(7.6 \%)$. The proportion increases with the level of education (3.3\% to 5.2\%). The proportion is $15.9 \%$ among intermediate professions in teaching, health, public service (school teacher, educator, etc.) who have worked on site. For $38.5 \%$ this situation was accompanied by a deterioration in working conditions and for $3.6 \%$ by a significant decrease in income. $20.5 \%$ of those who have had an increase in their working hours report a deterioration in certain relationships (compared with $15.3 \%$ for all employed persons).

7. Some people have had to work unusual hours $(6.6 \%$ in our sample, for those in employment). This was more frequent for those who worked outside the home $(39.1 \%$ of those who had this obligation were in this case, $13.2 \%$ of those who worked outside had this obligation). It was also more frequent for intermediate professions in teaching, health, the civil service (school teachers, educators, etc.), $10.5 \%$, and professionals and managers in the public sector $(8.9 \%)$. The proportion of people in this situation increases with level of education (4.7\% to $7.2 \%)$. For $41.3 \%$ this situation was accompanied by a deterioration in working conditions and for $7.9 \%$ by a significant decrease in income. $23.1 \%$ reported a deterioration in certain relationships (compared to $15.3 \%$ among the employed), $26.2 \%$ declared having created new contacts (compared to $21.1 \%$ in the sample of employed people).

$32.6 \%$ of those who increased their working hours were also forced to work unusual hours (20.9\% the other way round). 
8. Taking all situations together, $13.3 \%$ of those in employment reported a deterioration in their working conditions during lockdown. This proportion is $32.9 \%$ for those who are teleworking and have experienced an increase in their working hours during normal working hours, $43.4 \%$ if in addition the hours are unusual. 21.3\% for P\&MS in the public sector and 17\% for intermediate occupations in the public sector. The proportion increases with the level of education (from $8 \%$ for the least qualified to $16.8 \%$ for the most qualified). $24.5 \%$ report a worsening of certain relationships (compared to $15.3 \%$ for all employed persons), $47.1 \%$ report the loss of certain contacts (compared to $37.4 \%$ ).

9. $10.9 \%$ of the people in our sample who had a job previously say they have seen their income drop significantly, especially among those who have reduced their working hours, with technical or partial unemployment or in other situations. $45.9 \%$ find themselves not working (compared to 19.8\%). 49.7\% of craftsmen and tradespeople are in this case, $24.6 \%$ of employees providing services to private individuals, $17.4 \%$ of blue-collar workers and $15.7 \%$ of managers in the public sector. $42.1 \%$ say they have lost contacts (compared with $37.4 \%$ ). The proportion decreases with the level of education (from $16.3 \%$ to $8.7 \%$ ).

To sum up, $45.3 \%$ of the respondents experienced no change in their amount of work or their working hours (none of situations 1 to 7), 47.5\% experienced a reduction in the amount of work (situations 1 to 4 ) and $7.2 \%$ experienced no change at all (situations 5 to 7 ). Those who reduced their volume of work were more likely to see a reduction in their income, while those who experienced changes without reduction were more likely to see a deterioration in their working conditions.

\section{Figure 6. Job-related changes according to the situation during lockdown}

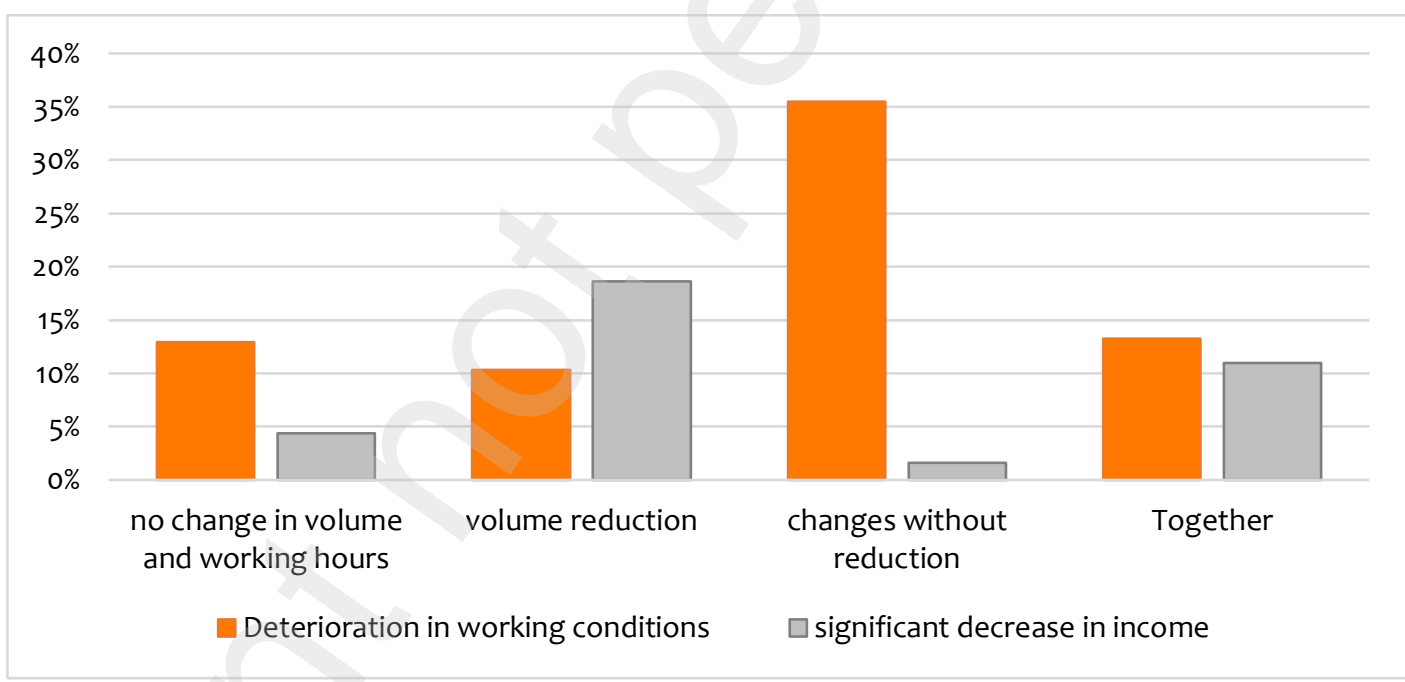

Source : Enquête

Vico, April-May 2020.

Field: Respondent aged 18 and over usually residing in France $(\mathrm{N}=16,224)$.

Reading: $12.9 \%$ of people who did not mention any change in the volume or hours of work report a deterioration in their working conditions.

\subsection{Varying situations according to professional categories}

As shown in the following graph, the situations have varied greatly according to occupational categories. 
Intermediate occupations in education, health and the civil service were the most in demand to adapt their schedules, return to work, increase the number of working hours. The reduction in the volume of work has mainly concerned the private sector professions. The public sector has been less affected by changes.

\section{Figure 7. Work and lockdown according to occupational categories}

all people who are employed

Worker (skilled or unskilled industrial or craft worker, driver, chauffeur, driver, etc.).

Employee in direct services to individuals (waiter, cleaning lady, childminder, salaried hairdresser)

Administrative or commercial employee in a company (reception officer, secretary, clerical worker, control, etc.)

Public employee (postal, tax, public administration, service agent, etc.).

Administrative or commercial intermediary profession in a company

Intermediate profession in education, health, civil service

Manager, professional or head of a company of at least 10 employees, higher intellectual professions, teachers

Craftsman, shopkeeper or manager with less than 10 employees
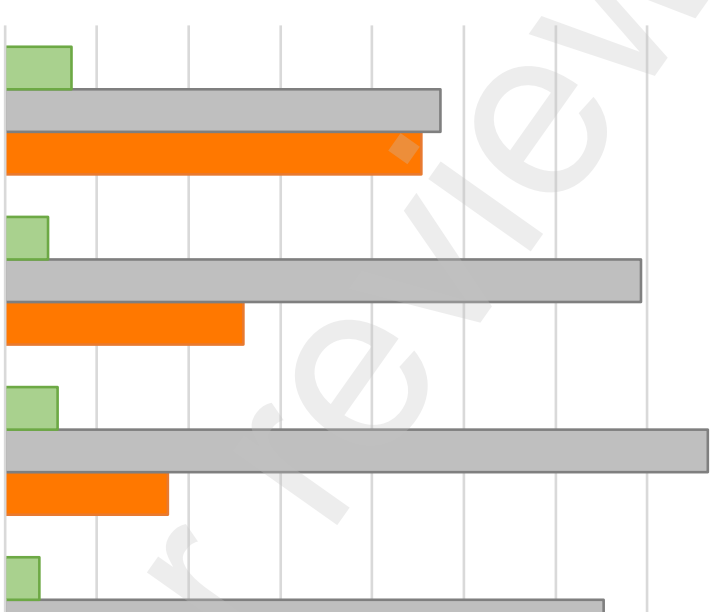

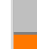

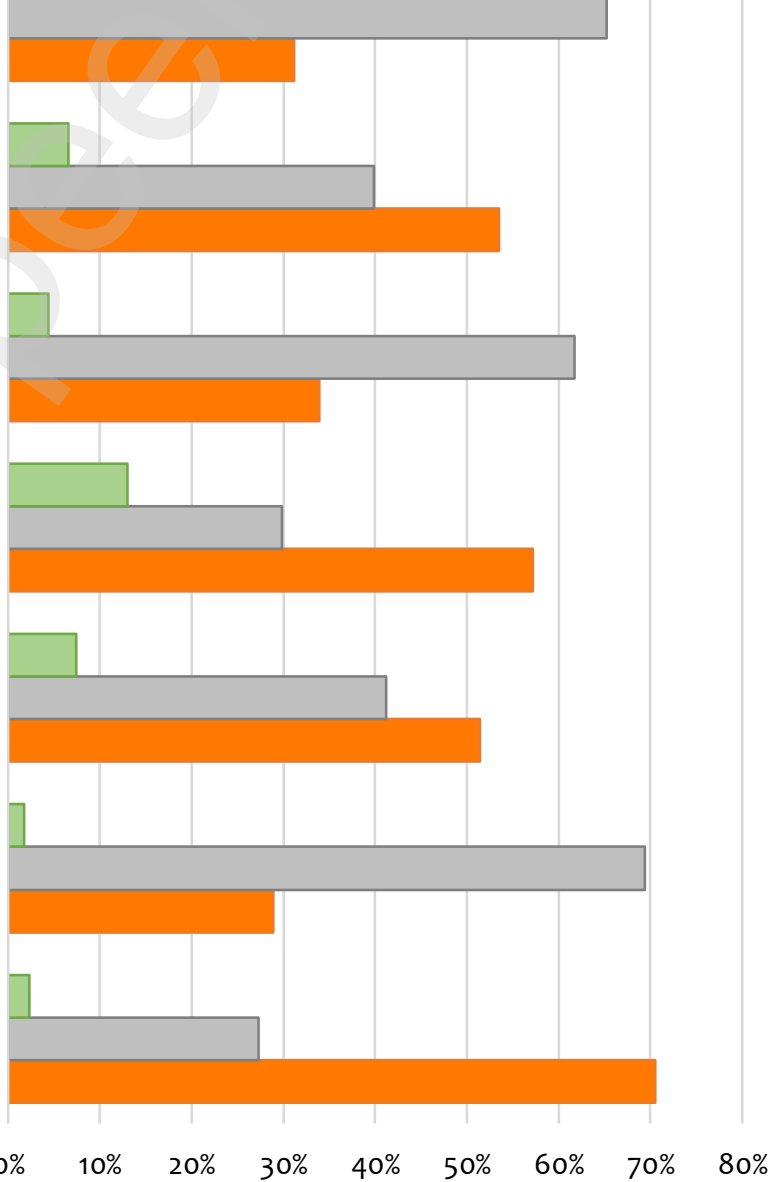

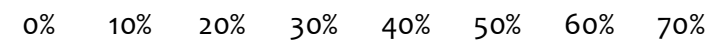

$80 \%$

$\square$ changes without reduction

$\square$ volume reduction

no change in volume and working hours

Source: Vico survey, April-May 2020.

Field: Respondents aged 18 and over usually residing in France $(\mathrm{N}=16,224)$.

Reading: $70.5 \%$ of farmers did not report any change in the volume and working hours. 
Among the people in employment who left comments at the end of the questionnaire, those who have experienced changes in work organisation without a reduction in volume are more likely to mention in these texts teleworking and ICT, teleworking and children, rhythms of life, problems posed by educational continuity, and fear of the virus. For their part, people who have seen the volume of work reduced refer more often than others to the fear of unemployment and issues relating to job insecurity and professional integration.

With regard to on-site work or teleworking, in certain categories (farmers of course, bluecollar workers, certain intermediate professions, particularly in the health field, some employees, blue-collar workers) many respondents went to their workplace, professional and managerial staff were teleworking on a massive scale, shopkeepers, craftsmen and a large proportion of employees and blue-collar workers had to stop working during the lockdown.

\section{Figure 8. Teleworking according to professional categories}

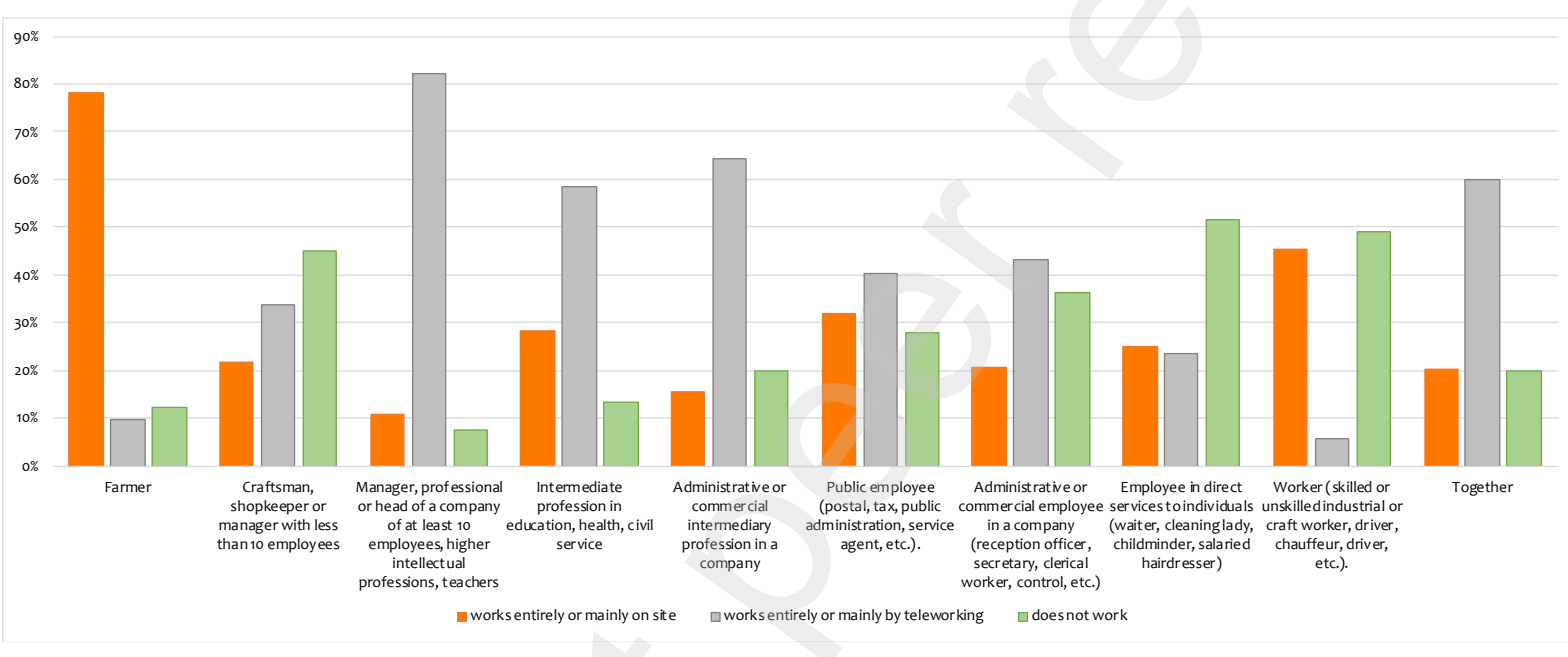

Source: Vico survey, April-May 2020.

Field: Respondents aged 18 and over usually residing in France $(\mathrm{N}=16,224)$.

Reading: $59.5 \%$ of farmers worked entirely at their workplace.

To sum up, teleworking has been very widespread among professional and managerial staff and members of the intermediate professions, with people in other professions either having to travel to their usual place of work more often or having to stop working temporarily.

\section{The evolution of relationships and personal networks}

One of the motivations behind the VICO survey was an interrogation of interpersonal relationships and the environment they constitute around each person, what social science researchers specialising in these issues call "personal networks". The situation created by confinement entailed very significant constraints on social interactions (talking to each other, working together, carrying out joint activities, etc.) which are the basis for the creation and maintaining of interpersonal relationships. Part of the questionnaire was therefore oriented towards capturing what could constitute for the respondents changes in relationships at the time of confinement: loss or deterioration of relationships, new contacts, strengthening of certain bonds, etc.

In order to analyse the relational logics, it should be borne in mind that this survey began approximately one month after the start of confinement (April 14) and ended with its conclusion 
(May 10). The respondents therefore had a minimum of one month of confinement and a maximum of two months. These are short durations on the scale of interpersonal relationships, the temporality of which is in line with that of life courses. We should therefore not expect radical transformations of personal networks. However, for most of the questions focusing on changes in relationships, a very large majority of the respondents replied by reporting changes, at least temporary ones. This is of course partly due to the orientation of the questions, but proves too massive to be totally artificial, all the more so as we asked specific questions that allow us to explain these changes in more detail.

In what follows, we begin an exploration by age categories (18-30, 31-60, over 60). We then examine the differences between men and women, followed by the question of homophilia, the fact of frequenting people who share certain characteristics (age, level of education, family situation, etc.).

\subsection{Age: the sociability of young people experienced by confinement}

The effect of constraints on interactions and gatherings was most pronounced among the youngest (18-30 years old), whether single or recently married, childless, very committed to friendly sociability. They were unable to maintain certain links, created others, particularly with neighbours, as in the other age groups, but also and online, which is more specific to them.

Figure 9. Proportion of respondents reporting loss of contact

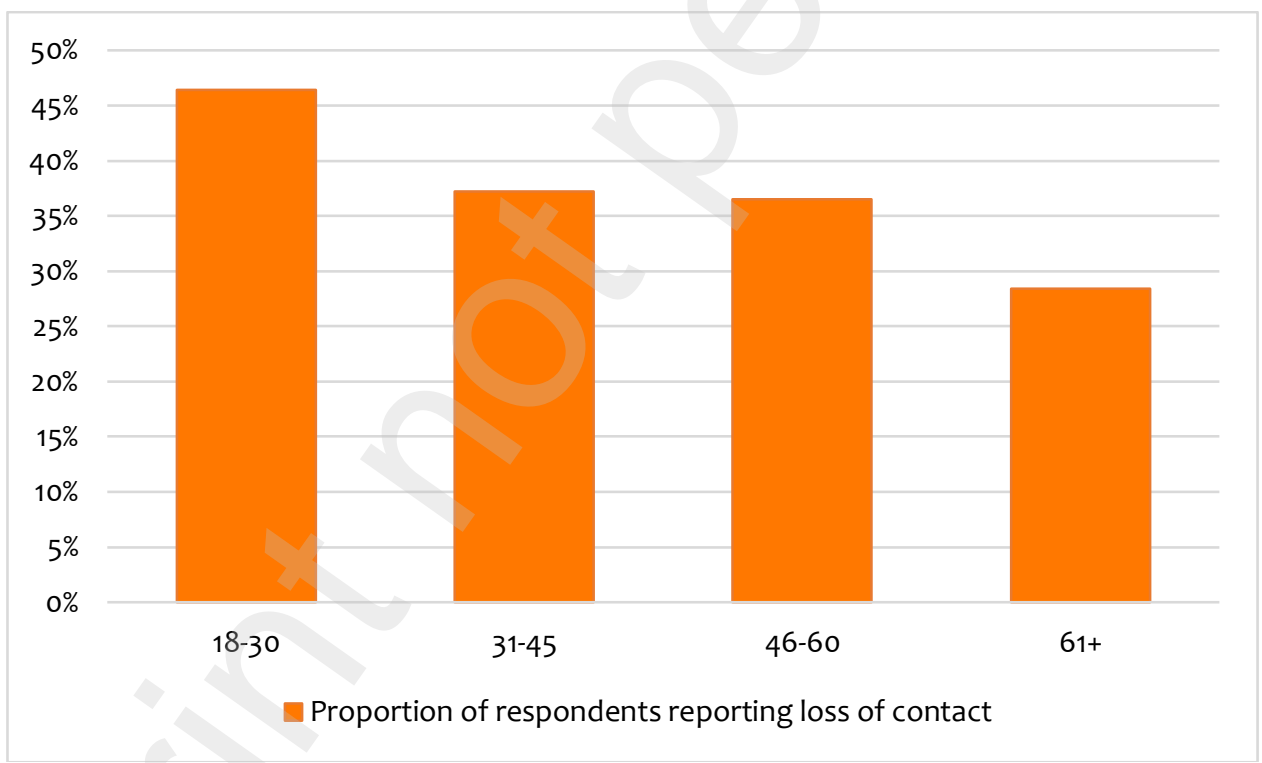

Source: Vico survey, April-May 2020.

Field: Respondents aged 18 and over usually residing in France $(\mathrm{N}=16,224)$.

Reading: $46.4 \%$ of $18-30$ year olds mention loss of contact.

For the majority of the youngest respondents, lockdown was a particularly important test of sociability and social relationships. The very many who returned to their parents' home to confine themselves maintained family ties better, sometimes at the cost of tension and a deterioration in relations with their parents or close family, but they had to give up more than the others exchanging as frequently as before with some of their friends. It would also seem that one of the effects of the crisis (and of the confinement) is the multiplication of family contacts, whereas friendly contacts are more impacted, both more lost and less contacted. This may lead us to reflect on the differences between these two relational roles, and on their specificity in a crisis context. 
For the 31-60 year olds, the relational logics varied greatly according to the work situation on the one hand, with the particular case of people who had to work longer or staggered hours, and according to the family and confinement configuration on the other hand, with the particular difficulties experienced by people confined alone. People who have experienced changes without a reduction in volume cite new contacts a little more frequently $(24.5 \%$ compared with $21.1 \%$ on average in this age group) and a deterioration in certain relationships $(19.5 \%$ compared with $15.3 \%)$. They also more frequently say they exchange less often with their family $(15.2 \%$ versus $10.7 \%$ ) and friends (30.5\% versus $23.9 \%$ ).

While there were differences in the work situation, the pattern of confinement was also an important aspect of life during this period. For people confined as a couple, with or without children, it is often the family ties that people say they lack. Lockdown also provided an opportunity to interact more than before with neighbours. Sometimes this led to the creation of new relationships, or the strengthening of already existing ones, but it should also be said that a great many testimonies (and this is reflected in the statistical analyses) refer to conflicts with neighbours (who make noise, do not respect the confinement, are aggressive, etc.), especially in buildings. People who find themselves confined alone (13.6\% in this age group) present particularities in terms of social relations. Confinement has been a particular constraint for these people by greatly reducing face-to-face exchanges. Their answers to our questions bear witness to this particular situation.

In many respects, the oldest of our respondents (over 60 years old), who are more wealthy than the average for their age group in France, were less troubled in their relationships than people in other age groups. Fewer of them lost sight of people they knew (28.4\% compared with 46.4\% of 18-30 year olds). They were also less likely to make new contacts. The most frequent testimonies among the over-60s basically say that lockdown is going well because living conditions are comfortable (the notion of privilege comes up very often in the testimonies of this age group), that distance communication has been widely used, but that direct contact with children, grandchildren (much cited), friends, and sometimes also people they meet in the context of association activities, is very much lacking. In addition to family ties, which are kept at a distance but whose physical contact is sometimes cruelly lacking, one aspect of confinement in this age group concerns associative activities, in which retired people are very involved. However, loneliness comes up quite frequently in the comments of people who are not or no longer in a couple and who find themselves confined alone: "The most terrible thing is loneliness" (1385, woman, 73 years old, retired lawyer, alone); "I have been widowed recently and the confinement adds to the depth of my loneliness. "(81500, woman, 74 years old, retired nurse, alone). Solitudes already existing before the confinement were reinforced by the situation, sometimes to the point of placing people in distress.

In this particular situation, people of all ages turned first and foremost to family or close friends, caring for their health and well-being, providing emotional support, sometimes material and practical help, and also benefiting from the same support in return. This is a classic result of studies on personal relationships, which is that, in emergency or crisis situations, people rely primarily on the "strong" ties of people they trust and close friends. However, weaker links (colleagues, neighbours, associations) have also been tested, sometimes strengthened, sometimes weakened. A selection has been made, perhaps on a long-term basis. New links were created, often with neighbours, since digital technology was a less important source of new relationships, including for young people, even if, as we mentioned above, they made much greater use of it than respondents in other age groups.

Differences related to educational attainment or occupation are found where sociologists expect them to be, given what is known about variations in personal networks along these dimensions. It is difficult to know at this stage of the analysis whether lockdown has played a role in reinforcing or reducing differences in personal networks. Because of its biases, our sample does not capture the least qualified in trades in the "blue-collar" category. 


\subsection{Women more involved in maintaining social ties}

Women were more involved in maintaining social ties, whether they were more or less close family or weaker ties (neighbours, acquaintances). In a context where part of the working relationship has been pushed aside, it is women who, as is the case in ordinary situations, but even more intensively in this new situation, have been the most invested in maintaining the other types of ties, particularly in the area of social support. Within couples, it is often the women who have taken charge of the monitoring of joint relationships: "I have not mentioned relationships with my children because it is often my wife who takes the initiative and I follow their situation very closely. "(2874, man, 67 years old, retired civil service executive).

\section{Figure 10. More contact with family or friends by gender}

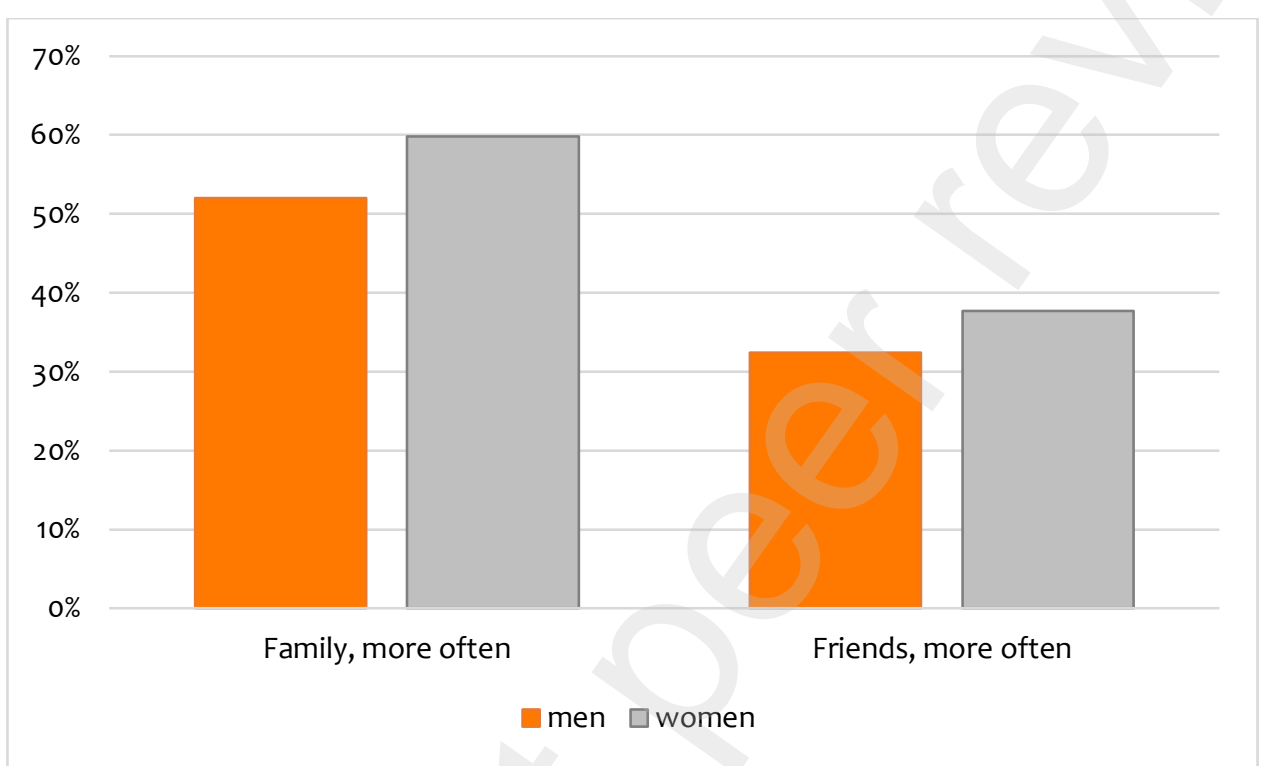

Source: Vico survey, April-May 2020.

Field: Respondent aged 18 and over usually residing in France $(\mathrm{N}=16,224)$.

Reading: $52 \%$ of male respondents said they contact their family more often.

Women are generally more likely to take on this type of task within couples. In a context where maintaining relationships was seen by most people as particularly important, they were often "on the front line" to use a war metaphor that was used a lot during this period. Among people living alone, the differences are attenuated, but in this situation there is also a greater involvement of women in maintaining relationships with the family beyond direct ascendants or descendants (grandparents, uncles, aunts, cousins), on a register of social support.

\subsection{Social homogeneity has increased}

Lockdown has had the particularity of having both constrained our interactions and at the same time left us partially free to choose the people with whom to maintain contact, confide in us, exchange ideas, etc. If we compare with data from previous surveys, we observe that, on the whole, the relationships that were maintained and strengthened during confinement concern much more than in "ordinary" times people with similar social characteristics, confinement seems to have reinforced a form of self-confinement. This phenomenon is particularly visible for educational level, $53.1 \%$ of the relationships strengthened during confinement were relationships between people of the same educational level compared to $44.9 \%$ in a comparable survey of personal relationships in 2018. This is the case for all degree level categories but the mechanism is slightly 
different according to the level of education. For the most highly educated it is colleagues and friends who are concerned by this increase, as these people often live in very homogenous environments in terms of degree (especially work or studies). $61 \%$ of the friends with whom the respondents with a level of education of 4 years or more have strengthened their relationships during the confinement are of the same level of education, compared to $49 \%$ of their friends in normal times. On the other hand, for the less educated, neighbourhood relations have particularly brought a sense of togetherness, as these people more often live in socially homogeneous environments (rural areas or underprivileged neighbourhoods). Registered friends are also more often of the same level of education as in normal times.

\section{Contrasting feelings during lockdown}

The questionnaire included a question on feelings: "Since the beginning of the confinement, have there been times when you have felt? "with a series of possible answers and space to suggest further formulations or explanations.

The frequency of the answer "none of the above" is significantly higher among men, increases with age (it is especially high among older people) but decreases with increasing level of education: $0.7 \%$ among the most educated women aged $18-30$ and $21 \%$ among the least educated men over 60 .

We have grouped the answers into four main variables, keeping the answers on fatigue and anxiety, which are very frequent and correlated with most of the others, and grouping together on the one hand the expressions expressing suffering (irritation, stress, sadness) and on the other hand those which seem to indicate a certain serenity (relaxed, fit, happy).

The frequency of the response indicating fatigue decreases with age. On average, women say they are more tired than men. The difference is small for young people (up to the age of 30), but then increases with age, especially for those with children, many of whom have had to manage their work, children and a large part of the household chores at the same time. For those over 30, the frequency of this response increases with educational attainment. If we combine these characteristics, we observe significant variations: $80 \%$ for women over 30 with a level of education above the baccalaureate, as opposed to $19.2 \%$ for men over 60 with a level of education below the baccalaureate. Taking gender, level of education and age into account, this type of response is more frequent among those who mention the existence of degraded relationships or suspended contacts, but also among those who cite new contacts.

The response indicating concern is highest for the 31-45 age group (first part of working life), decreasing in the upper age groups and more limited for younger people. In all age and education configurations it is higher for women. It is particularly high for women aged 31-45 with a low level of education $(72 \%)$ and lowest for men with a low level of education over 60 years of age $(39.9 \%)$. Taking gender and age into account, this type of response, like the previous one, is more frequent among those who mention the existence of degraded relationships or suspended contacts, but also among those who cite new contacts.

Responses indicating a certain degree of suffering ("irritated", "stressed", "sad") are very present among the youngest people and less and less so as age increases. In all configurations of age and degree these responses are more frequent among women. When combined with age, we observe contrasting situations: $43.7 \%$ among men over $60,90.8 \%$ among women between 18 and 30. Taking gender and age into account, this type of response is, like the previous two, more frequent among those who mention the existence of degraded relationships or suspended contacts, but also among those who mention new contacts.

The observation on the correlations with the variables relating to the evolution of relationships is the same for all these responses: this type of response, indicating states of fatigue, 
anxiety or suffering, seems to be more frequent in cases of relative relational instability linked to the situation of confinement.

This is not the case for the answers which, on the contrary, indicate serenity, or even the relatively pleasant character of the situation ("relaxed", "fit", "happy"). The frequency of these responses increases markedly with the level of education (and also, but somewhat less markedly, with income or socially valued professions). Taking the level of education into account, this frequency rather increases with age until the age of 60 , and then declines thereafter. If we remove the people who also ticked answers that also express suffering, then men seem to choose this type of answer more often. It is known that men are more inclined than women not to show weakness and therefore to under-report possible suffering, and to say that all is well. $76.7 \%$ of young people (18-30 years) with a baccalaureate level of 4 or more tick this type of response, whereas this is the case for only $25.9 \%$ of those over 60 with a low level of education. Contrary to the responses seen so far, these responses are more frequent for those who have not reported any deterioration in relationships, are slightly less frequent for those who have reported suspended relationships and significantly more frequent for those who have reported making new contacts and those who say they communicate more often with family or friends or those who do not report any change in this respect.

Many people ticked both responses expressing distress and responses relating to serenity. These are mostly young people, with the frequency of this type of response decreasing markedly with age. The age taken into account, it also increases clearly with the level of education. Taking these two criteria into account, women give this type of response more often. They are present in $70 \%$ of women aged 18 to 30 with the highest level of education and in $16.1 \%$ of men aged over 60 with the lowest level of education. These variations are probably largely due to different levels of attention to one's own feelings and the expression of these feelings. However, they also say something about the emotional tension associated with situations of emergency and uncertainty.

Very few respondents (19) did not tick off any of the proposed answers to these questions on feelings. On average they ticked four. This explains the responses that express contradictory feelings but which reflect a changing and complex reality: "Worried about the future of my job. Zen about the current situation. "(2259, 29-year-old student); "At first I was stressed because I work at the hospital, only one subject the covid and my dentist spouse who didn't work was very stressed and didn't want to hear about it! "(3671, 59-year-old woman, physiotherapist). Their answers indicate significant contrasts between those who experience confinement as a source of suffering (more often young people and women, reporting difficulties in maintaining their usual sociability) and others as a calming moment (older, more often men, mostly rather favoured, having formed new relationships and increased their exchanges with family and friends). There is therefore a clear link between the way the situation was experienced emotionally and the effects of this situation on personal relationships. Finally, the period during which the questionnaire was completed does not seem to have a clear effect on the feelings expressed once gender and age are taken into account.

\section{The rules of containment were not respected identically by all respondents.}

Lockdown implies a general ban on movement. During the period, several circumstances could thus be considered as transgressive: going out for more than an hour, exceeding one kilometre in the context of leisure activities, not having a certificate when going out or modifying it so that it complies in the event of a check (or having several), finding people outside the home. 


\section{Figure 11. Levels of transgression}

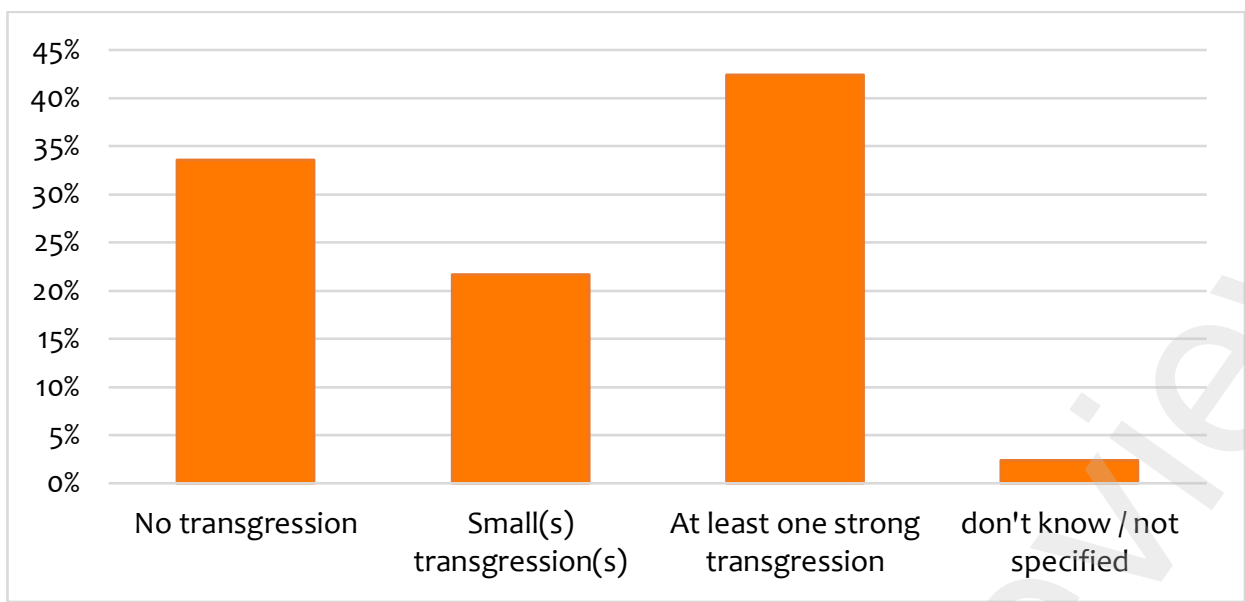

Source: Vico survey, April-May 2020.

Field: Respondents aged 18 and over usually residing in France $(\mathrm{N}=16,224)$.

Reading: $33.6 \%$ of respondents reported no transgressions.

Some of the respondents did not break any of the rules (33.6\%) and others only did so on the fringes, on rare occasions going out for more than an hour and/or beyond the kilometre $(21.7 \%)$.

Women are particularly present in the group that complied with the rules of confinement. There are also more young people under 45 years of age, people in employment or in the home, rather in city flats and in regions that have been more affected by the pandemic (Ile de France and the Grand Est). These elements suggest that the people who have followed the rules most strictly are those who have experienced it the most; they are also the ones who express the most negative feelings such as anxiety, fatigue, stress and sadness.

$42.4 \%$ of the population surveyed said they had broken at least one of the four rules mentioned in the questionnaire, but these were broken at different levels.

\section{Figure 12. Frequency of transgressions}

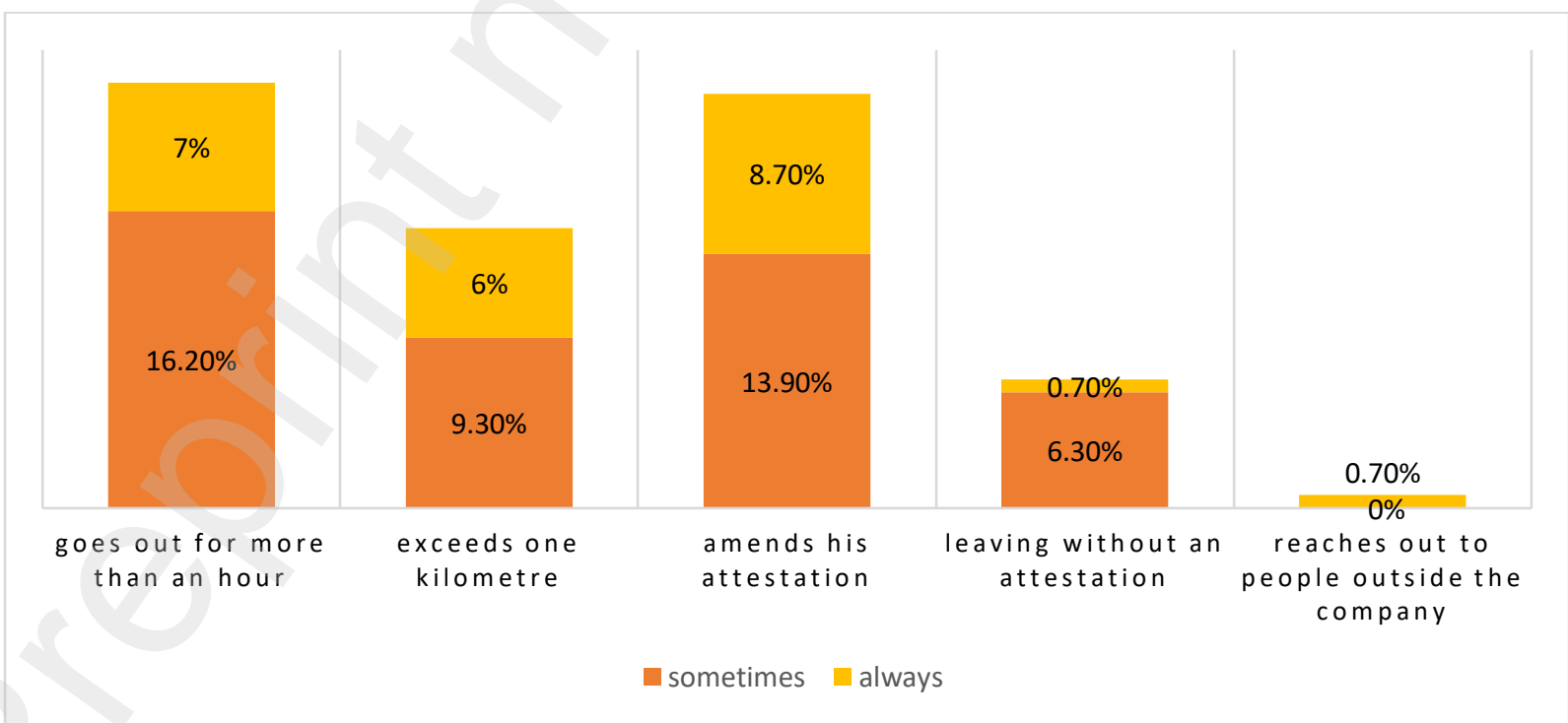

Source: Vico survey, April-May 2020.

Field: Respondents aged 18 and over usually residing in France $(\mathrm{N}=16,224)$.

Reading: 15.9 of the respondents declared going out sometimes for more than an hour. 
Nearly a quarter of the population (23.2\%) reports going out for more than an hour a day for walks or sports. This is more than those who regularly exceed the authorised kilometre limit $(15.3 \%)$ but very comparable to the proportion of those who say they tamper with their certificate to comply $(22.6 \%)$. On the other hand, the proportion of respondents leaving without a certificate is relatively low $(6.8 \%$ of the population surveyed). People from different households who get together during the walks only represent $0.7 \%$ of the respondents.

The social profiles are not the same according to the rules broken. We can understand here that depending on their situations, the opportunities to break the rules are not the same.

There are more people living in the countryside and older people among those who say they go beyond the authorised time of exit, as if the space available and free time could encourage this kind of transgression. The profile is similar to that of those who report exceeding the authorised kilometre, with the difference that they seem on average younger and more qualified. In both cases, they more often live in regions that are not very affected by the pandemic in spring (the Mediterranean and the south-west in particular).

Having modified the certificate or having several when leaving has rather concerned people with more modest incomes, in buildings and flats and of middle or advanced age. The (very few) people who declare going out regularly without a certificate are also of modest income, but on the other hand are younger and more often in studies, work experience or training. Like the previous ones, they are more numerous in regions that have been little affected by the pandemic. Here, the difficulty in producing the certificate as a material object may also have been partly responsible for these behaviours, since they are the ones who more often declare that they have to make handwritten certificates.

In reality, very few people contravene the four main rules $(2.6 \%)$, and it seems rather that identifiable groups of people only transgress one or two rules, in ways that remain to be better defined. Imposed on everyone, respected by a large part of the population, the rules of confinement have not been tested in the same way by everyone.

\section{The specificities of the regions most affected by the epidemic at the time of the survey}

The survey was completed in all French regions thanks to the help of the Daily Regional Press, to whom we extend our warmest thanks.

Île de France is by far the region in which people have changed accommodation for confinement (15.7\% compared to $8.7 \%$ for the whole sample, $33.8 \%$ for those under 30 ). Somewhat less markedly so in Auvergne Rhône Alpes (12.2\%, 36.1\% for those under 30). In both cases, this is mainly explained by the high proportion of students in our sample for these regions and secondarily by the higher proportion of professional and managerial staff (who may have secondary residences).

While there is little difference between most regions in terms of feelings, the Great East stands out clearly. The feeling of fatigue is particularly present there $(72 \%$ versus $61.8 \%)$, as are feelings of worry $(67.5 \%$ versus $62 \%)$ and expressions of suffering $(83.5 \%$ versus $76 \%$ ), which cannot help but be related to the intensity of the epidemic in this region. But it is also in this region that we find an over-representation of expressions of serenity ( $61.6 \%$ against $56.6 \%)$. It therefore seems that the inhabitants of this region have been more emotionally affected than others. The Great East is also characterised by a higher frequency of declarations of lost relationships $(40.8 \%$ versus $37.6 \%)$ and of degraded relationships $(19.9 \%$ versus $15.6 \%)$. In the case of degraded relationships, more often than elsewhere, we find situations of deterioration in the relationship with the spouse with whom the respondent is confined (16.9\% versus $12.4 \%)$. It should be noted that in the Paris region, the Seine Saint Denis presents the same trends as the Grand Est. As far as 
the evolution of relations with the family is concerned, the Grand Est is characterised by the highest frequency of reporting a reduction in communication (13.6\% against $10.9 \%)$. The region is joined in this respect by the Hauts de France (14\%). The same is true for friends $(26.2 \%$ for the Grand Est, $25.9 \%$ for the Hauts de France, against $23.4 \%$ for all those surveyed). The difference tends to be concentrated in intermediate professions and employees. For both types of relationships, the Ile de France region is characterised by a greater frequency of responses evoking an increase in communication (especially the most highly qualified).

\section{Conclusion and overview: a very unusual event that needs to be studied further}

These are only the first results of a survey that has yielded a large volume of data on different aspects of life during lockdown. The sample contains significant statistical biases, but most social profiles are sufficiently represented and the volume of data allows for effective comparative analysis.

$8.2 \%$ of the respondents have changed accommodation for confinement. This proportion is particularly high among young people, many of whom have moved to their parents' home, or to their spouse's parents' home when they are in a couple, and settled there with them. When age is taken into account, it can be seen that the most highly educated over 45 years of age have changed their place of residence for the lockdown more frequently than others. In all age groups, the proportion of people who have changed accommodation is particularly high among people living alone in a flat. If we combine those who have changed accommodation, those who have taken in relatives or friends, and those who have seen someone living with them leave at the time of confinement, it is one person in five whose housing composition has changed on this occasion.

These population movements mean that, in our sample, the proportion of people confined alone is limited (less than 16\%). The majority were in couples (63.4\%), most often with children $(32.7 \%)$, sometimes with other people (parents, friends, etc.). Men were most often separated from their children, which can be explained by the many cases where the mother retains primary custody of the children after separation.

About two thirds of the respondents were working before lockdown. Their work situation in the context of lockdown In all age groups, the proportion of people who have changed accommodation is particularly high among people living alone in a flat. If we combine those who have changed accommodation, those who have taken in relatives or friends, and those who have seen someone living with them leave at the time of confinement, it is one person in five whose housing composition has changed on this occasion.

These population movements mean that, in our sample, the proportion of people confined alone is limited (less than 16\%). The majority were in couples (63.4\%), most often with children $(32.7 \%)$, sometimes with other people (parents, friends, etc.). Men were most often separated from their children, which can be explained by the many cases where the mother retains primary custody of the children after separation.

About two thirds of the respondents were working before lockdown. Their work situation in the context of lockdown varied greatly depending on the type of occupation. In certain categories (farmers of course, blue-collar workers, certain intermediate occupations, particularly in the health field, certain employees, blue-collar workers), relatively large numbers of respondents visited their workplace. Professional and managerial staff (P\&MS) were very heavily involved in teleworking, shopkeepers, craftsmen and a large proportion of employees and workers had to stop working. Intermediate occupations in education, health and the civil service were the most in demand to adapt their working hours, return to work and increase the number of working hours. The reduction in the volume of hours worked has mainly affected the private sector professions. People who have experienced changes in working conditions (increased working hours, staggered working 
hours) without a reduction in volume are slightly more likely than others to mention changes in relationships (deterioration of relationships but also new contacts), and express fatigue more often than others. On the other hand, people who have seen a reduction in the volume of work say they are more often serene, but more often mention fear of unemployment, job insecurity and problems of professional integration.

Lockdown was perceived by the respondents as having effectively tested and sometimes changed their personal relationships. The effect of the constraints on interactions and gatherings was most pronounced among the youngest respondents, who were single or recently married, childless, very committed to friendly sociability. They were unable to maintain certain links and created others, particularly with neighbours or people they met online, but in smaller numbers. For those who went to live with their parents, who were very numerous among the students, the new cohabitation with the previous generation sometimes strengthened ties and sometimes created tensions. Maintaining friendships was more difficult in this situation. For those in employment, the relational logics varied greatly according to the work situation on the one hand, with the particular case of people who had to work longer or staggered hours, and the family and confinement configuration on the other hand, with the particular difficulties experienced by people confined alone. The older people in the well-off categories who replied saw their relationships less disrupted by the situation, which appeared to them to be less of a rupture than for their younger counterparts, even though some people living alone experienced increased, or even unbearable, loneliness.

In this particular situation, people turned first and foremost to family or close friends, caring about their health and well-being, providing emotional support, sometimes material and practical help, and also benefiting from the same support in return. This is a classic result of studies on personal relationships, which is that, in emergency or crisis situations, people rely primarily on the "strong" ties of people they trust and close friends. However, weaker links (colleagues, neighbours, associations) have also been tested, sometimes strengthened, sometimes weakened. A selection has been made, perhaps on a lasting basis. New links have been created, often with neighbours, since digital technology has been a less important source of new relationships, including for young people, even if they made much greater use of it than respondents in other age groups.

Women were more involved in maintaining social ties, whether these were more or less close family or weaker ties (neighbours, acquaintances). In a context where part of the working relationship has been set back, it is women who, as is the case in ordinary situations, but even more intensively in this new situation, have been the most invested in maintaining the other types of ties, particularly in the register of social support. Within couples, they have contributed more than men to maintaining interpersonal relationships.

People confined alone more often than others experienced difficulty in maintaining a social life. Being confined alone was a particular experience in all age groups, but it did not have a similar effect on interpersonal relationships. For the young people, this situation was an opportunity to rebuild friendships, sometimes positively experienced, whereas in the other age groups it more often led to more or less painful experiences of loneliness.

Finally, outside the family, the relationships that were strengthened during this exceptional situation most often involved people whose level of education was similar to that of the respondents. This survey on confinement confirms in this respect the tendencies towards social homogeneity that have already been detected in other studies and it is possible that these tendencies have increased as a result of the crisis.

The answers to the question on feelings during confinement indicate significant contrasts between those who experienced confinement as a source of suffering (more often young people and women, reporting difficulties in maintaining their usual sociability) and others as a time of relief (older, more often men, especially those who were more favoured, having formed new relationships and increased their exchanges with family and friends). There is therefore a clear link between the way the situation was experienced emotionally and the effects of this situation on personal relationships. 
Geographically, differences between regions are rare but significant. It is very clearly in the Ile de France region that there were the most people leaving to confine themselves to somewhere other than their usual accommodation. These were mainly young people moving back to their parents' homes and secondarily professionals with second homes. On most of the other indicators we can discern what is probably an effect of the pandemic with the Grand Est region standing out on most of the variables. It is as if people in this region have been more affected than others both emotionally (more expressions of fatigue, anxiety, suffering, but also of serenity) and in terms of relationships (more loss of relationships and deterioration of relationships). In a mitigated form, some of these tendencies can be found in the Hauts de France and the Ile de France with a particularity on the Seine Saint Denis.

The initial analyses from the VICO survey provide a better understanding of the situations experienced during the lockdown of spring 2020 in France. Lockdown caused a sudden and general rise in a health crisis and disrupted the living conditions of millions of people, both in terms of family life and work. This disruption has also affected interpersonal relations, which have been severely tested and may change over time as the crisis continues. More generally, this confinement has been a test for all, although a significant minority have experienced it as a calming moment. Further analysis of the data from this survey and further surveys will be necessary to understand the full implications of this unprecedented crisis. 